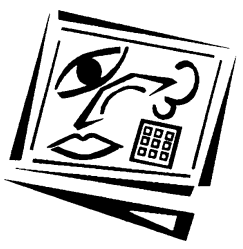

\title{
Long-term student experiences in a hybrid, open-ended and problem based Adventure Learning program
}

\author{
George Veletsianos \\ University of Texas at Austin \\ Aaron Doering \\ University of Minnesota
}

\begin{abstract}
In this paper we investigate the experiences of elementary school children over a twoyear period during which they engaged with a hybrid Adventure Learning program. In addition to delineating Adventure Learning experiences, we report on educational technology implementations in ecologically valid and complex environments, while drawing inferences on the design of sustainable and successful innovations. Our research indicates that the Adventure Learning experience over the two-year period was dynamic, participatory, engaging, collaborative, and social. Students eagerly became part of the experience both inside and outside of the classroom, and it quickly became apparent that they saw themselves as valued members of the unfolding storyline that mediated their learning. Our recommendations for future research and practice include a call to evaluate "authenticity," focus on the learner experience and narrative, and consider the interplay between pedagogy, technology, and design.
\end{abstract}

The learner's journey through a lesson, week, or semester (whether online or face to face) is often complex and multi-faceted (c.f. Parrish, 2008). What is paramount in this experience is our understanding of why and how a learning experience was effective, valuable, interesting, engaging, and possibly transformational (Wilson, Parrish \& Veletsianos, 2008). This journey, the experience of learning, is the focus of this paper. Specifically, we investigate the experiences of elementary school children over a twoyear period during which they engaged with a hybrid Adventure Learning program. Our purpose is multifold:

- First, from an evaluation standpoint, we are interested in understanding the learner experience when students participate in Adventure Learning projects.

- Second, we are interested in investigating the implications of educational technology innovations in ecologically valid environments.

- Finally, we are concerned about the sustainability of technological, pedagogical, and design interventions in education, and are interested in understanding the successful implementation of long-term, technology enhanced learning endeavors.

To introduce the reader to the topic of investigation, we first explore the problem based learning approach upon which our Adventure Learning curricula are founded. Second, we introduce open ended learning environments in which our projects are situated. Third, we discuss the interconnections between Adventure Learning, problem based learning, and open-ended learning environments, and introduce GoNorth! as the adventure learning program to be investigated, along with prior 
research on student experiences in this program. Next, we present our research questions, method, methodology, and findings. Finally, we conclude by discussing the findings and making recommendations for future research and practice regarding the design and evaluation of electronic learning environments, and the learner experience.

\section{What is problem based learning?}

Problem based learning (PBL) is a curricular and instructional approach to learning where students learn by solving ill-structured or complex problems (Boud \& Feletti, 1997; Hmelo-Silver, 2004; Savery, 2006). Importantly, the PBL approach also encompasses notions of situated cognition (Brown, Collins \& Duguid, 1989), authentic scenarios (Doering et. al, 2009), collaborative practices (Bransford, Brown \& Cocking, 1999), and scaffolding (Hmelo-Silver, Duncan \& Chinn, 2007). While the PBL approach to learning is aligned to the constructivist school of thought, successful problem solving is structured, guided, and scaffolded (Hmelo-Silver, Duncan \& Chinn, 2007). Notably, learning through problem solving is not a new approach to learning: initially applied to medical schools, PBL methods spread to numerous professional areas. Yet, K-12 teachers have been slow to adopt PBL models of teaching (Dahlgren, Castensson \& Dahlgren, 1998). The reasons for this slow adoption may lie in the multiple challenges that PBL introduces to the classroom environment, such as the development of a collaborative culture (Ertmer \& Simons, 2006). Naturally, low levels of PBL implementation in the K-12 classroom also mean scarce research on PBL in K-12 contexts (Goodnough \& Cashion, 2006), even though content areas as diverse as science (Goodnough \& Cashion, 2006), history (Saye \& Brush, 2007), and geography (Doering \& Veletsianos, 2007) have seen PBL advances.

\section{What are open-ended learning environments?}

Open-ended learning environments (OELEs) gained popularity as contemporary locales of student-centered learning activity, as places which support constructivist theories and student-centered pedagogies (Land \& Hannafin, 1996). Simply put, if learners actively pursue and construct knowledge, make choices about what, how, and when to learn, then learning environments that provide flexibility and allow learner control and self direction, support student-centered pedagogies and theories.

OELEs can exist face to face, online, or in hybrid modes. For instance, in face to face modes, a teacher can provide different colour light bulbs and pieces of coloured glass to her science classroom for students to explore the properties of light and colour; in online learning settings, a teacher can engage his students in a similar exercise by designing an interactive exercise within a virtual world; finally, in a hybrid education mode, a teacher can provide her students with online resources that scaffold their real life experiments towards understanding the properties of colour (e.g., Valanides \& Angeli, 2008).

\section{Adventure Learning, PBL and OELEs}

Adventure Learning is an approach to the design of learning experiences that focuses on real world issues in authentic and collaborative settings (Doering, 2006, 2007; Doering \& Veletsianos, 2008a; Veletsianos \& Kleanthous 2009). The approach is based on notions of inquiry and experiential (Kolb, 1984) education, where the learner engages with complex issues (e.g., political crises) identified in a curriculum and 
mediated by technology, co-learners, teachers and experts, a narrative situating the learning experience, and the adventure upon which the experience is based. To date, the literature presents five Adventure Learning projects that have been explicitly developed based on the Adventure Learning principles (Veletsianos \& Kleanthous, 2009). These projects are collectively referred to as GoNorth! and were designed and developed at the University of Minnesota in partnership with NOMADS Online Classroom Expeditions. In these projects, students and teachers worldwide follow a team of explorers and educators that dogsled live through Arctic locations of the world, drawing linkages between the curriculum, the region of travel, and the issues involved. The team sends media artifacts, such as audio and video, from the trail to document the adventure. The media highlight the links between the curriculum and the real world, while at the same time fostering interaction between learners, teachers, and experts. Such interactions are hosted in an Adventure Learning environment and vary from real time chats with experts on a focused topic (e.g., climate change) to weekly reports (e.g., explorer experiences on the trail).

While the relationship between adventure learning, problem based learning, and openended learning environments is implicit in the description of adventure learning presented above, an explicit presentation of the features they share may enable the reader to better understand this approach. At the very basic level, adventure learning and PBL are approaches based on student inquiry, grounded on the understanding that learning is a process whose end result may vary across students. In addition, curricular and instructional activities are primarily situated and authentic and need not be based on a single correct answer. Adventure learning requires the use of adventure based education, technology, and collaboration. While PBL may encompass these features, it does not necessarily require them and can be implemented without them. Finally, adventure learning and PBL share the notion of a narrative or storyline: in PBL the problem to be solved is presented in the context of a story, while in adventure learning the learners are following a storyline through which real world problems are presented.

The adventure learning approach is also frequently mediated by an online learning environment, which is a variant of open-ended learning environments. Specifically, adventure learning environments are OELEs in the sense that they provide flexible spaces for student exploration, experimentation, and engagement with topics of interest. While support may be provided in the adventure learning environment (e.g., weekly tasks, curricular activities, and scheduled chat sessions), the environment is neither directed nor deterministic, making it appropriate for hosting activities that are student oriented, such as those arising from the PBL approach. For instance, students can listen to the explorers' audio updates, use their location coordinates to map their route, and send encouragement notes to the expedition team.

\section{Learner experiences with Adventure Learning}

Although adventure learning research has examined students' learning experiences in the past, the learner experience over long periods of times has not been investigated (Veletsianos \& Kleanthous, 2009). While short-term student experiences may be helpful in fine tuning interventions and situating how the long-term experience is likely to unfold, it is imperative to understand students' extended learning experiences because of the long-term nature of some adventure learning programs. 
Adventure learning research with respect to the learner experience has mostly focused on elementary and middle school children. One of the persistent findings in the literature has been the engaging nature of the adventure learning approach: learners enjoy participating in adventure learning experiences, exhibit behavioral changes as a result of participating in such projects, and discuss their experiences outside of their classroom, often leading their parents to request from teachers continued use of the adventure learning curriculum (Doering \& Veletsianos, 2008a, 2008b).

Additionally, project participants consistently note that they enjoy interacting and collaborating with the explorers' team and other students, teachers, and experts across the world (Doering, 2007; Doering \& Veletsianos, 2008a). While it is possible for adventure learning curricula to be completed within classrooms in an individualistic basis, the majority of the classrooms researched have actively sought to implement adventure learning projects on a collaborative basis. Collaborative features utilised included classroom participation in weekly chats, classroom postings on collaborative online spaces, sharing of student artefacts, and discussions around online student postings.

Finally, adventure learning projects appear to have yielded transformational learning outcomes (Doering \& Veletsianos, 2008b). For instance, students have not only learned content (e.g., climate change, sustainability, flora, fauna), but have also taken steps to make a difference outside their classrooms by encouraging and educating others to make behavioural changes consistent with what they learned (e.g., by convincing their parents to drive less to reduce their environmental footprint). While these outcomes may indicate that the adventure learning approach has been successful, the long-term nature of these projects necessitates extended research over long-term periods of time to understand the temporal dimensions of the learning experience.

\section{Research questions}

To satisfy the aims and purposes of our research, we pose and answer the following questions:

1. What are students' long-term experiences with adventure learning?

2. What are the factors influencing sustained engagement with adventure learning?

3. How do technology, pedagogy, and design mediate successful long-term adventure learning experiences?

\section{Method}

\section{Study design}

In this study, we employed a panel study approach of thirty students who looped with the same teacher over a period of two years (looping is the practice where the teacher stays with his/her students more than one year and moves with the students to the next grade level). The long-term study of these students' experiences occurred within a real world implementation of the Adventure Learning project studied. In particular, the design, implementation, and evaluation of the program occurred simultaneously, with data gathered before, during, and after the intervention. In turn, the data were utilised to revise and refine both the intervention and the Adventure Learning approach to education. The reason for this process lies in the fact that the Adventure 
Learning intervention occurred in the context of a complex and real life classroom, away from a controlled laboratory setting (Brown, 1992; Collins, 1992; The DesignBased Research Collective, 2003).

\section{Participants and context}

This study is informed by 30 students (18 females, 12 males) in one public elementary school in a large Midwestern suburb. Students' eligibility for free or reduced price lunches is usually used as a proxy for socio-economic status; in this district less than $5 \%$ of the student population receives free or reduced lunches, indicating that, on average, students in this elementary school can be considered to be of high socioeconomic status.

Participants used the GoNorth! Arctic National Wildlife Refuge 2006 and GoNorth! Chukotka 2007 Adventure Learning programs in their 4th and 5th grade classrooms (between 9 and 11 years old) during the 2005-2007 academic years. The 2006 program can be accessed at: http://www.polarhusky.com/2006/home2006.asp. The 2007 program is available at: http:/ / 2007.polarhusky.com/. The teacher - Mr Johnson (all names used in this paper are pseudonyms) - with whom the students looped had been teaching for twenty years and was motivated by and committed to the Adventure Learning program. In a previous study exploring how teachers integrate Adventure Learning programs in their classroom (Doering \& Veletsianos, 2008a), we found that Mr Johnson integrated the Adventure Learning program using a mix of constructivist and directed methods, focused on the authentic and experiential nature of the program and the accompanying online learning environment, and creatively bridged the gap between his classroom and the real world. In addition, $\mathrm{Mr}$ Johnson was well-versed in the use of technology and had frequent and open access to a networked computer lab. On average, the computer lab was used twice per week.

\section{Data sources}

The data corpus informing this study consist of 24 classroom observations conducted over a period of 2 years (February 2006 to May 2006, and February 2007 to May 2007), 12 focus groups with participating students, and 8 personal interviews with the participating teacher. Classroom observations occurred twice per month for the periods of January-June 2006 and January-June 2007. Classroom observations in January and June indented to capture the classroom environment outside of the implementation of the Adventure Learning program. Focus groups were once per month for the periods of January-June 2006 and January-June 2007. Personal interviews with the teacher were conducted once per month for the periods FebruaryMay 2006 and February-May 2007.

Classroom observations focused on student and teacher activities and sought to document the teacher's practice (e.g., pedagogies, activities, classroom management) and the students' behaviours and attitudes (e.g., interest, curiosity, responsiveness). Focus group questions were open-ended and were intended to provide space for the students to share their experiences. Follow up questions were frequently used to elicit further information from the students. Finally, during the interviews the teacher was asked to reflect on his practice and on his students' experiences. 


\section{Data analysis}

Under the interpretive research paradigm umbrella, our research employed a case study research method (Yin, 2003), where the aforementioned classroom represents the case under investigation. We chose this method because we wanted to describe, understand and explain complex and multi-layered events that occur in authentic situations (Haas Dyson \& Genishi, 2005). To analyse the available data and develop themes and patterns, we used the constant comparative method (Glaser \& Strauss, 1967). Specifically, each author analysed data independently and noted emerging patterns. The authors then met thirteen times to discuss their individual findings. At each meeting the data were re-analysed and triangulated across data sources in order to confirm and disconfirm evidence for the patterns. This process continued until consensus was reached between the authors and data saturation emerged (i.e. further data analysis yielded no new insights).

\section{Findings}

Data revealed that students who used the Adventure Learning program engaged in sustained interactions with the project, content, experts, and with each other. Furthermore, we discovered that the teacher implementing the Adventure Learning program practiced varied pedagogical strategies that afforded diverse learning experiences. To illustrate these findings, we present three themes: (a) long-term experiences, (b) sustained engagement, and (c) the relationship between technology, pedagogy, and design to mediate the learning experience.

\section{Students' long-term learning experiences}

Visceral connection

Throughout all focus groups, students described the connection they felt to the GoNorth! Adventure Learning series. At every focus group held, students commented that they looked forward to Monday mornings to see what "has happened over the week" and would check for updates on their computers at home before they went to school. Trail updates were posted online every Monday for the duration of the expeditions (14 trail updates for 2006 and 13 trail updates for 2007). In addition, students showed a deep understanding of numerous aspects of the online expedition (e.g., understanding of the impact of climate change on traditional travel conditions such as dog sledding) and the curriculum (e.g., understanding that local actions have global implications). We came to understand and describe their learning and understandings as "ownership." In other words, the learners felt such a strong connection to the experience that they came to "own" the experience, speaking about it as if they were part of the expedition, adventure, and story. This visceral connection was identified through a variety of program elements and was revealed through discussions detailing the GoNorth! Team, describing the polar huskies (i.e. the sled dogs), exploring the relationship to the geographical place and native people, and delineating how they collaborated with other students across cultures.

For example, students consistently described the intimate details of all expedition members and their role within the Adventure Learning program. Jimmy said, "Mille has been traveling throughout the Arctic for many years. She is from Denmark and she is one of the expedition leaders. She runs a dog team and she knows the people in the Arctic very well." The students talked about the team members as if they were acquainted for years. Sam said, "I know the explorers very well. They have been 
traveling throughout the Arctic delivering the [education program] to us for two years." When the authors visited the classroom for the first time, the connection to the Adventure Learning program was immediately revealed through students' introductions. Each of the students stood on their chairs, introduced him/herself, and in detail introduced the dog they "adopted." Sally, for example, said, "My name is Sally and my dog is Freja. Freja is a lead dog and is the mother of Beacon." It is important to highlight the fact that, in the focus group sessions, twenty-nine out of thirty students discussed their connection with the team and used words such as "family," "team," and "group" to describe this relationship.

The students noted that they felt that they were as important as any other students participating in the program, while also stating that the GoNorth! team had made them feel "special" due to the fact that their voice was being heard in the online learning environment via the opportunity to add their own thoughts to the project. For example, the students had created "Polar Husky t-shirts" that were mailed to the team in the Arctic. The team displayed these t-shirts in the online report, delivering a sense of presence and excitement to the students.

The visceral connection described was not limited to the team and the dogs; students also felt a connection with the landscape and its people. In detail again, students described the Arctic, and discussed aspects of the Arctic that they learned from the trail reports and from the curriculum. They understood that the Arctic is a place that is more than ice and snow, but is a location that is impacted by climate change, is a place where animals, such as polar bears, live, and a place that varies greatly throughout the circumpolar region. Students knew the Arctic people, the issues facing the Arctic, and were able to describe the people and the issues in detail. John, for instance, said, "In Russia [the 2007 program], we saw the Yaranga and the reindeer herding people. Then, the cool thing is that we felt that we were there. We saw pictures and videos of Mille and Aaron in the Yaranga with the Chukchi people. They were cooking reindeer. Then there was a picture of all of them together" (Figure 1). Twenty-six out of thirty students throughout the focus groups shared details of the Arctic people and the issues facing the Arctic region.

One experience we had not dreamed of was our visit with the Chukchi reindeer herders. Making our way across the tundra in yet another mind boggling vehicle, 5 -foot high tires (1 2/3 meter) mounted with a jeep, and once again kindly guided by the mayor of Lorino, Andree Gino, it was with the greatest possible anticipation we saw the yaranga appear on the snow covered tundra in the distance while we could see the reindeer herd to the north. This time of the year the reindeer herders have separated the cows away from the bulls so that they can give birth to their calves. A small group of herders take the cows towards the coast and northwards for good grazing on the tundra in cool and breezy conditions.

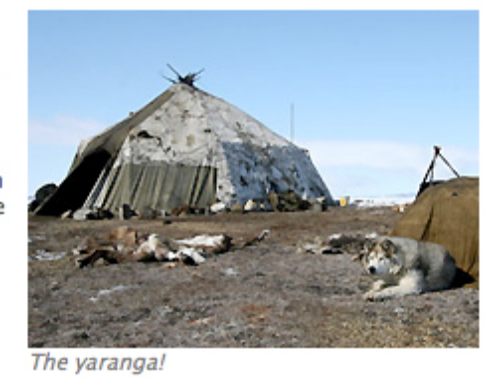

Figure 1: Text and media describing the people and issues of the Arctic

The connection to the people throughout the Arctic also extended to cultures across the world. Students in the classroom we studied described working with fellow students whom they had never met, but who had posted their projects within the collaboration zones and participated in the synchronous chats. Students not only described other students' projects in detail, but also discussed exactly where their colleagues lived and what it is like to live at those places. Marion said, "I am able to talk with others throughout the world and it is so easy to do. I can also see who I'm collaborating 
with," while Jan highlighted the fact that she likes to share her work with others, "I like to be able to share my projects with other students... and to hear what they think about our work and about the team and about the dogs and the Arctic." Frank, in a very exciting manner, also revealed his enthusiasm about connecting with others and the possibility of a worldwide audience, "We would post our projects and the next day it was for all the world to see!"

\section{Narrative and closure}

When students described their experiences with Adventure Learning, twenty-eight of them described the story in which they participated and "loved to read and investigate." Eric said, "We loved to go to the computer labs to read the updates. It was so much fun to see what was happening next and I just really wanted to be there." Sara said, "I really did feel like I was there with the team, especially Mille. I was so excited that she was there and was one of the leaders." The story behind the experience and the unfolding of the explorers' lived experiences in the Arctic were two of the most referenced items during the focus groups. Students made references to conflicts that arose on the trail (e.g., deciding on the best approach to cross a particularly difficult terrain), survival (e.g., ensuring enough food is available for the team and the dogs), and bravery (e.g., enduring the risks of dogsledding in the Arctic [Figure 2]). These storytelling features seemed to capture the students' attention and imagination (c.f., Egan, 1986) and invite them to immerse themselves in the experience.

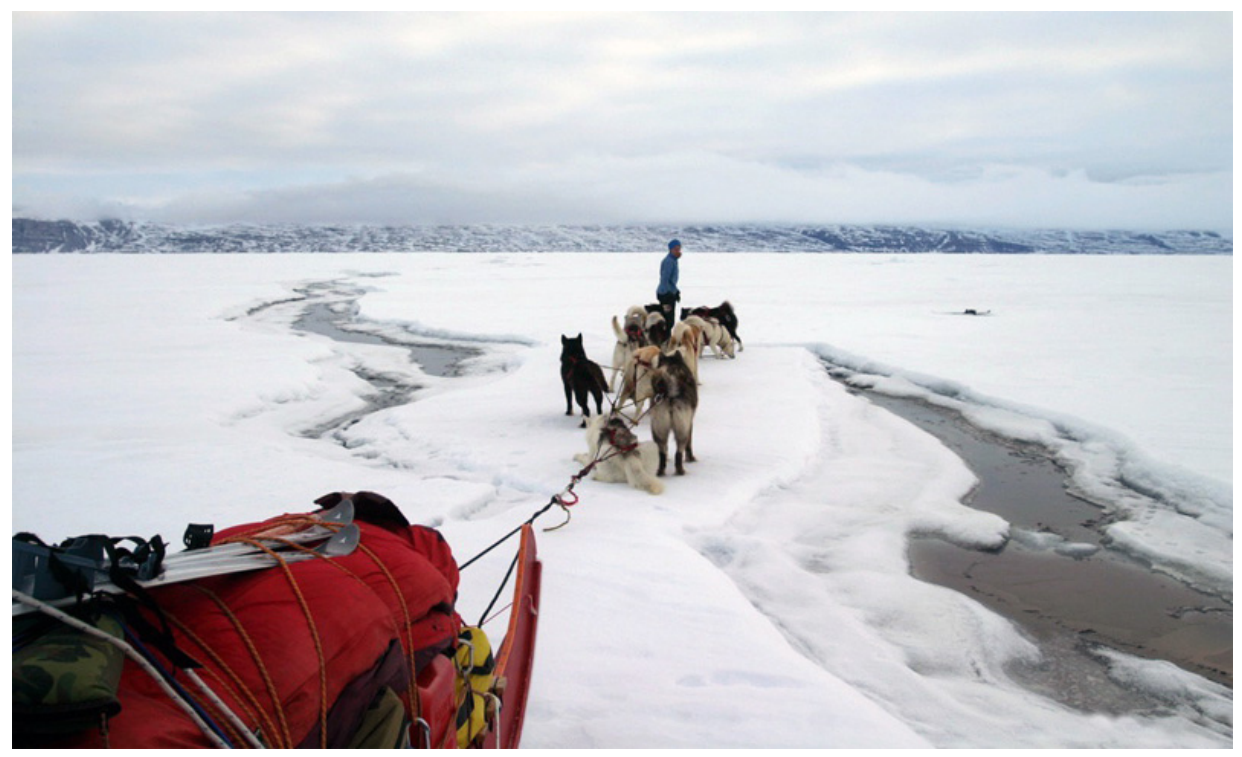

Figure 2: Team GoNorth! balances on a pan of ice to cross the lead and avoid falling in the Arctic Ocean

Equally important, students noted that it was difficult for the experience to end, as they wanted to "continue following along." For example, in 2006 the GoNorth! team ended the expedition with a detailed account of arriving to their destination in Prudhoe Bay, Alaska. However, the students and Mr Johnson were upset that the "team never said goodbye." Jesse said, "It just seemed like they disappeared and the entire class was pretty sad. We wanted to say goodbye to them." The students needed 
closure as they felt that they were part of the team. As a result, since 2006, the final trail reports focused on bringing closure by (a) showcasing student work, (b) ensuring that the the GoNorth! team thanked students for their participation, and (c) sending students a farewell message.

\section{Dynamic learning}

Dynamic learning refers to the energetic, open-ended, and diverse nature of participating in an Adventure Learning program as described by the students. Billy said, "I never was bored, unlike my other classes. It just seemed there was always something for us to be doing and learning. I liked to watch the movies, see the pictures, and play the online games." Sue said, "My favorite part of GoNorth! was that we could post our projects and then we could participate in the chats with others from around the world." The dynamic nature of the experience the students described was a result of bringing multiple elements together (e.g., collaboration zones, expert chats, trail reports) to give students an encompassing and open-ended learning experience such that each individual or group of individuals could partake in the experience via any means that they found appealing.

\section{Students' sustained engagement}

During the two years of this study, students' interest in and engagement with the program continued to grow. For example, at the end of the first year and at the beginning of the second year, students asked Mr Johnson if he was "going to use GoNorth!" as they wanted to be "part of the next expedition and the next trip to the Arctic." Mr Johnson described the students' involvement as a "sustained interest over time that did not waiver... The students looked forward to this part of the school year, and they loved it." In this section, we describe two aspects relating to the students' sustained interest: the first relates to learning that transfers to outside-of-classroom activities and the second relates to the "hook" of the program, the dogs, that were able to capture and sustain student interest.

\section{Beyond the classroom}

Both students and Mr Johnson described numerous activities that represented engagement in and beyond the classroom. For example, at home, students asked their parents and guardians to visit the online learning environment so they could share with them what they were doing in school. Jeff for instance, said, "I have my parents log-on to polarhusky [the Adventure Learning website] so I can show them what I'm doing. It is so much fun to show them this whenever I can." Additionally, sixteen out of thirty students (over 50\%) stated that they did an activity outside of class that was not assigned by Mr Johnson. For example, students wrote letters to the local television station to let them know they are traveling to the Arctic without leaving their classroom and raised $\$ 1,200$ through fundraising to help adopt a dog and give money to an environmental organisation. Lucy said, "As a class, we wanted to raise money to make a difference, just like polarhusky is doing. We wanted to do more than study about something, we wanted to get involved and the great thing was that we could do it for more than one year."

The "hook"

Mr Johnson noted that over two years, he saw a connection the students had to the "hook" of the program - the dogs. As he described, "there are many online learning environments, but not too many pull the students into the environment where they 
[the students] consistently want more. The difference with the GoNorth program is that the dogs were part of the students' experiences - they were the hook that kept the students coming back for more." In turn, the students described their experiences with the polar huskies and how they encouraged and motivated them to come back. For example, students knew the many minute details of the dogs and followed the Arctic travels with the team and their dog that many had adopted as part of a class activity. Susan said, "I adopted Buttra last year and he is my dog that I follow throughout the year." Michael said, "My dog is Ginger and she is who I look for during every week." The connection that the children felt to the dogs, the "hook" of the program, was further solidified when the researchers visited the students before the beginning of the second year of the expedition and took a dog with them. This action served to highlight the real world aspect of the program and curriculum and introduced a vivid authenticity to one of the most appealing characters of the adventure. We will return to this point at the implications section of the paper where we discuss how interest in the program was sustained throughout its duration.

\section{Technology, pedagogy, and design mediating students' experiences}

The final theme that emerged from our investigation was the idea that technology, pedagogy, and design, in coordination, mediated the learning experience. In other words, neither technology, nor pedagogy, nor design can be said to be fully and individually responsible for the successful outcomes associated with this experience. When teaching and learning are thought of in the context of these three interrelated issues, it becomes evident that only by understanding the relationships between these three issues can we enhance technology mediated education.

Mr Johnson described in detail how it was clear to him that the GoNorth! Adventure Learning program was guided by ideas and theories that assisted student learning. He also exhibited an awareness of the principles guiding Adventure Learning and discussed how he found the design of the program "purposeful." For example, he noted that there are no disparate activities between the curriculum and the online learning environment, and that the modules are appropriately scaffolded for his students (e.g., trail reports, photos, and videos are module specific). The collaborative features of the approach and environment also appealed to the teacher, especially because they were well integrated with the learning experience as opposed to being add ons, "That [opportunities for collaboration] is the one of the major strengths of Adventure Learning - allowing my students to talk and interact with other students, experts on the topic, and the explorers in the field."

The design of the Adventure Learning curriculum was based on three levels of pedagogical integration - "Experience, Explore, and Expand." These three levels range from a general directed approach to teaching content to a problem based investigative approach. Mr Johnson appreciated this flexibility because he was able to choose the pedagogical approach that was best for his particular context and students, "I used the experience level to introduce some topics, but I found to truly use the web site, I wanted my students to be at the explore and expand level." The affordances provided by the design of the curriculum and the learning environment allowed the teacher flexibility in integrating adventure learning in his classroom and an opportunity to modify his approach depending on his current needs. The design of the Adventure Learning environment, with its multiple activities and pedagogical options, assisted in enabling the teacher to flexibly integrate this program in his classroom over the two years of this 
study. Mr Johnson noted, "The students were never bored. I can try to give myself a pat on the back, but I'm sure it is because there are just so many activities that help students learn the content - ranging from the curricular activities to the videos."

Nevertheless, Mr Johnson is a creative teacher with an acute ability to see connections between the Arctic expedition and his students' daily lives. This ability allows him to design appealing activities grounded on the content and interactions within the Adventure Learning program. He is able to guide students through the numerous media and resources available to them via the Adventure Learning site and is able to scaffold their learning. Given the open-ended nature of the Adventure Learning environment, unguided explorations of the site would have been ineffective and inefficient; Mr Johnson understood this and his scaffolding of student exploration is indicative of his strong teaching abilities.

\section{Discussion and implications}

These findings suggest pedagogical and design considerations that may be fruitful for the design of long-term online learning interventions (see Figure 3). These ideas are discussed next.

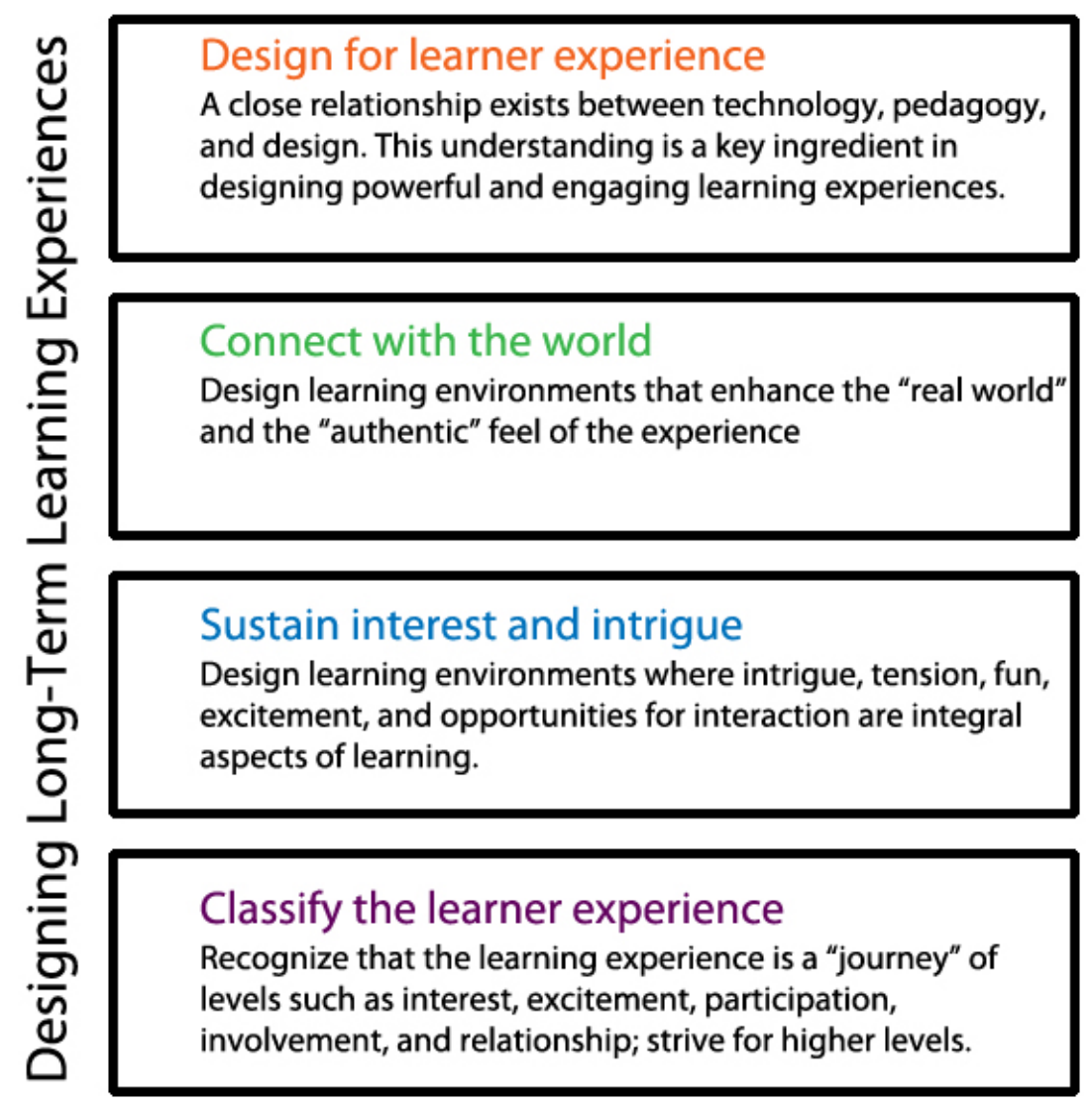

Figure 3: Designing for long-term learning experiences 


\section{Sustain interest and intrigue}

Apart from a few well-known exceptions (e.g., Quest Atlantis and River City), the majority of educational technology interventions are either short-term or short-lived implementations of a tool or innovation. This is especially true of implementations grounded on new technological tools because the fast rate with which technology develops quickly renders new tools obsolete. The current five-year life span of the GoNorth! project and the two-year study of its implementation outlined in this paper shed light on how an educational innovation can sustain the interest and imagination of participants. Importantly, one of the most valuable findings of this study seems to be the power that lies in participatory stories and narratives. Prior research has also indicated that stories and narrative foster enjoyment, sense making, creativity, and imagination (Hokanson \& Fraher, 2008; Frykman, 2009), and may provide a context through which contemporary learning experiences can be delivered. In this project for example, learners enjoyed the unfolding narrative and intriguing nature of a team of explorers traversing the Arctic, with its unexpected outcomes and imaginative storytelling. In addition, they enjoyed being contributors to the story and the experience. They helped the team by raising money and discussing the issues raised in the story with their family and colleagues; they also participated in conversations with experts and sent encouraging notes to the explorers.

Interest in the learning endeavour was sustained not merely by the content itself, but by the activities build around the content and the opportunities provided to the learners for participation, the majority of which could not have been possible without the use of social technologies. By building intrigue, tension, fun, excitement, and providing opportunities for interaction, the Adventure Learning approach enabled sustainable engagement with learning that transcended the walls of the classroom. Our field should actively seek ways to design engaging learning experiences that are sustained over time. To do so, future work should investigate how to bridge the gap between classroom instruction and out-of-classroom experiences in locations of interest. Implicit to this idea is the notion that new and emerging technologies allow and foster creative explorations of out-of-classroom settings. Future research could, for example, explore the efficacy of these issues by investigating Adventure Learning deployments in various contexts.

\section{Design for learner experience}

The findings of this study have revealed the close and reinforcing relationship that exists between technology, pedagogy, and design. The previous paragraph, for example, discusses how pedagogy (e.g., features of storytelling) can create intrigue and anticipation in learners' minds. Yet, this pedagogical approach is most effective when coupled with contemporary technological tools that allow the expedition team to easily and effortlessly bring to life various parts of the narrative (e.g., by using videos and photographs of events that occurred on the trail). In addition, the design of the learning environment and curriculum was supportive of the teaching, and flexible enough to allow both teacher and students to forge their own path in the experience. For instance, when using a module, a teacher is given a calendar showcasing different possibilities of how to use the program along with a variety of activities that would allow her/him to pursue the curricular goals that $\mathrm{s} /$ he considers most important. The flexibility, multiplicity, and adaptability built into the program allowed the teacher and students to engage with the program over long periods of time without being exposed to repetitive experiences. 
Importantly, open-ended learning environments allow learners to engage with learning experiences in multiple ways, leading to learning experiences/journey that are not uniform or monolithic. This idea reflects the philosophy behind open-ended learning environments with regards to flexibility and self-direction, but instead of focusing on the environment the focus here is on the experience. For example, some learners may be satisfied with reading the trail updates posted every Monday, but others may continue exploring the resources contained within the learning environment. The implications for research and design are far reaching: can designers plan learning experiences for objectives like engagement, interest, and intrigue, especially in open-ended learning environments? If so, how, and to what extent are such strategies successful? The researcher's task is equally complicated: On what basis are non-uniform learning experiences to be evaluated? What makes learning experiences engaging to some students but not to others? Can we devise guidelines for engaging and powerful learning experiences when learning varies with learner willingness and predisposition to engage with learning materials/activities?

\section{Connect with the world}

Researchers and practitioners often highlight the benefits of connecting learners to the "real world," in what is usually referred to as authentic (Bruner, 1986; Vygotsky, 1978) and experiential learning. While the terms authentic learning, experiential learning, and the "real world" may not have a uniform meaning, during our two-year study we realised that the Adventure Learning program described herein encompassed a degree of authenticity that extended beyond what is usually thought of as "authentic." To clarify, the Adventure Learning curriculum provided what may be deemed to be "standard" forms of authenticity: real world problems, images and video that enhance the learning experience, and synchronous chats with experts. While these activities are worthwhile, we realised that we had enacted further actions that served to enhance the "real world" and "authentic" feel of the experience, and that these actions proved to be very powerful and engaging. Examples of such actions included:

- Visiting the classroom and bringing one of the dogs along,

- Showcasing physical student creations on the online learning environment (i.e. the "Polar Husky t-shirts"),

- Answering student questions or replying to encouragement notes.

Student responses to these seemingly simple actions revealed their value and importance. These actions not only highlighted the real world nature of the program, but also helped facilitate strong bonds between the classroom and the explorers. Literature on these issues is lacking. Therefore, we see a need for research to evaluate and delineate (a) authenticity in online learning environments, and (b) the development of relationships and bonds between learners and what they are learning. Of particular importance are future investigations aimed at devising ways to (a) provide expanded opportunities for authentic interaction and engagement, and (b) foster the development of bonds between learners and content. In particular, research into strategies to truly connect classrooms and the real world, along with research on the outcomes and implications of these strategies are urgently needed. While field trips have received considerable attention as tools to open up classroom walls (Taylor, Morris \& Cordeau-Young, 1997), we see a need to explore how technology can (a) enhance such learning experiences, and (b) make such virtual experiences more effective and engaging. For instance, current technological advances in augmented 
reality, location aware devices, and location based social services may provide the technological momentum for online learning environments that connect learners to the physical world, advancing opportunities for authentic engagement.

\section{Classifications of the learner experience}

Throughout this paper we discussed the learner experience and alluded to items such as learner excitement, anticipation, participation, and interest. Our work in this classroom over the two-year period has highlighted the fact that the learner experience is a journey (Parrish, 2008). This journey is not a uniform and linear experience rather, it varies and is subject to modifications, and additions, enhancements, and drawbacks. This journey can also be seen through levels via which designers and researchers could strive to invite learners to participate. At the very basic level, for example, one can see interest: the student becomes interested in the experience. At the middle levels, we could place excitement and participation: the learner becomes enthusiastic about the opportunities afforded and begins to participate in the experience (e.g., by initiating conversations). At the higher levels of this classification, we could place involvement and relationship: the learner becomes immersed in the experience and extends the experience beyond the opportunities provided to him/her by the learning environment (e.g., by raising awareness about the issues outside of the classroom setting, or by remixing the media, content and opportunities provided). The learner may even forge a personally meaningful relationship with the content or issue and actively pursue threads of interest that relate to the topic or content.

Developing such a classification, and viewing the journey of the learner through such a lens will allow designers and researchers to direct their attention to the design of technology enhanced learning experiences that are oriented towards higher level experiences. Instead of focusing on increasing student interest, designers and researchers should aim for higher goals, such as active learner participation and cultivating bonds between learner interests and content. We see this as a fruitful and valuable cause to direct future research endeavours.

\section{Conclusion}

In this study we sought to gain insights on students' adventure learning experiences during a two-year period, technology integration in ecologically-valid educational settings, and on what makes long-term educational technology interventions sustainable and successful. To this end, we engaged in a two-year panel study of thirty elementary school students who looped with the same teacher. Our findings suggest that the Adventure Learning experience was dynamic, participatory, engaging, collaborative, and social. While students eagerly participated in the learning experience both inside and outside of the classroom, it quickly became apparent that they saw themselves as being participants and actors in an unfolding narrative.

While the focus of this research has been on the long-term experiences of learners participating in an adventure learning project, our findings suggest future research and design directions not only for Adventure Learning, but also for technology enhanced education in general. Based on this investigation, designers and researchers are advised to cultivate the learning experience and consider its multidimensionality. In particular: 
- The learning experience consists of more than effective and efficient learning. Fun, engagement, appeal, and involvement are important components of powerful learning experiences. Yet, educational technology communities have disregarded the value of these ideas. Fun and engagement should be goals to strive towards when designing instruction. To assist designers with designing learning experiences that are engaging, fun, and appealing, we see a need for instructional design models that cater to these kinds of experiences.

- Learner interest and intrigue should be integral aspects of learning, but current instructional design models do not account for long-term involvement in learning. While it may be easy to initially engage learners in a topic, it becomes more difficult to maintain enjoyment and interest over longer periods of time. Future investigations towards such endeavours will be worthwhile.

- Future research should also focus on investigating the aspects of learning that motivate learners to (a) return to online learning environments, and (b) share their learning with individuals outside of their classroom/school. The development of bonds between learners and issues studied is of particular importance. A fruitful research direction is the development of strategies devised specifically to enable learners to form close connections and bonds with what they are learning.

Importantly, we see a need for 21st century learning to move beyond the delivery of efficient education and to focus on the development of learning opportunities that foster engagement, excitement, and participation.

\section{References}

Boud, D. \& Feletti, G. (1997). The challenge of problem-based learning (2nd ed.). London: Kogan Page.

Bransford, J. D., Brown, A. L. \& Cocking, R. R. (1999). How people learn: Brain, mind, experience, and school. Washington, DC: National Academy Press. http: / / www.nap.edu / openbook.php?record_id=6160

Brown, A. (1992). Design experiments: Theoretical and methodological challenges in creating complex interventions in classroom settings. Journal of Learning Sciences, 2(2), 141-178.

Brown, J. S., Collins, A. \& Duguid, P. (1989). Situated cognition and the culture of learning. Educational Researcher, 18(1), 32-42.

Bruner, J. S. (1986). Actual minds, possible worlds. Cambridge, MA: Harvard University Press.

Collins, A. (1992). Towards a design science of education. In E. Scanlon \& T. O'Shea (Eds.), New directions in educational technology (pp. 15-22). Berlin: Springer.

Dahlgren, M. A., Castensson, R. \& Dahlgren, L.O. (1998). PBL from the teachers' perspective. Higher Education, 36(4), 437-447.

Doering, A. (2006). Adventure learning: Transformative hybrid online education. Distance Education, 27(2), 197-215.

Doering, A. (2007). Adventure learning: Situating learning in an authentic context. InnovateJournal of Online Education, 3(6). [verified 4 Apr 2010] http: / / www.innovateonline.info/pdf/vol3_issue6/Adventure_Learning__Situating_Learning_in_an_Authentic_Context.pdf 
Doering, A., Scharber, C., Miller, C. \& Veletsianos, G. (2009). GeoThentic: Designing and assessing with technological pedagogical content knowledge. Contemporary Issues in Technology and Teacher Education, 9(3). http: / / www.citejournal.org/vol9/iss3/socialstudies/article1.cfm

Doering, A. \& Veletsianos, G. (2007). Multi-scaffolding learning environment: An analysis of scaffolding and its impact on cognitive load and problem-solving ability. Journal of Educational Computing Research, 37(2), 107-129.

Doering, A. \& Veletsianos, G. (2008a). Hybrid online education: Identifying integration models using adventure learning. Journal of Research on Technology in Education, 41(1), 101-119.

Doering, A. \& Veletsianos, G. (2008b). What lies beyond effectiveness and efficiency? Adventure learning design. The Internet and Higher Education, 11(3-4), 137-144.

Egan, K. (1986). Teaching as storytelling: An alternative approach to teaching and curriculum in the elementary school. Ontario, Canada: Althouse Press.

Ertmer, P. \& Simons, K. (2006). Jumping the PBL implementation hurdle: Supporting the efforts of K-12 teachers. Interdisciplinary Journal of Problem-based Learning, 1(1), 40-54.

Frykman, S. (2009). Stories to tell? Narrative tools in museum education texts. Educational Research, 51(3), 299-319.

Glaser, B. G., \& Strauss, A. L. (1967). The discovery of grounded theory. Chicago: Aldine Publishing.

Goodnough, K. \& Cashion, M. (2006). Exploring problem-based learning in the context of high school science: Design and implementation issues. School Science and Mathematics, 106(7), 280295.

Haas Dyson, A. \& Genishi, C. (2005). The case: Approaches to language and literacy research. New York: Teachers College Press.

Hmelo-Silver, C. E. (2004). Problem-based learning: What and how do students learn? Educational Psychology Review, 16(3), 235-266.

Hmelo-Silver, C. E., Duncan, R. G. \& Chinn, C. A. (2007). Scaffolding and achievement in problem-based and inquiry learning: A response to Kirschner, Sweller, and Clark (2006). Educational Psychologist, 42(2), 99-107.

Hokanson, B. \& Fraher, R. (2008). Narrative structure, myth, and cognition for instructional design. Educational Technology, 48(1), 27-32.

Parrish, P. (2008). Plotting a learning experience. In L. Botturi \& T. Stubbs (Eds.), Handbook of visual languages for instructional design: theories and practices (pp. 91-111). Hershey, PA: Information Science Reference.

Savery, J. R. (2006). Overview of problem-based learning: Definitions and distinctions. The Interdisciplinary Journal of Problem-based Learning, 1(1), 9-20.

Saye, J. W. \& Brush, T. A. (2007). Using technology-enhanced learning environments to support problem-based historical inquiry in secondary school classrooms. Theory and Research in Social Education, 35(2), 196-230.

Taylor, S. I., Morris, V. G. \& Cordeau-Young, C. (1997). Field trips in early childhood settings: Expanding the walls of the classroom. Early Childhood Education, 25(2), 141-146. 
The Design-Based Research Collective (2003). Design-based research: An emerging paradigm for educational inquiry. Educational Researcher, 32(1), 5-8.

Valanides, N. \& Angeli C. (2008). Distributed cognition in a sixth-grade classroom: An attempt to overcome alternative conceptions about light and color. Journal of Research on Technology in Education, 40(3), 309-336.

Veletsianos, G. \& Kleanthous, I. (2009). A review of adventure learning. The International Review of Research in Open and Distance Learning, 10(6), 84-105.

http:/ / www.irrodl.org/index.php/irrodl/article/view/755/1435

Vygotsky, L. S. (1978). Mind in society. Cambridge, MA: Harvard University Press.

Wilson, B., Parrish, P. \& Veletsianos, G. (2008). Raising the bar for instructional outcomes: Towards transformative learning experiences. Educational Technology, 48(3), 39-44.

Yin, R. K. (2003). Case study research: Design and methods (3rd ed.). Thousand Oaks, CA: Sage.

Dr George Veletsianos

Assistant Professor of Instructional Technology

University of Texas at Austin, USA

http: / / www.veletsianos.com/, http:/ / www.twitter.com/veletsianos

Dr Aaron Doering

Associate Professor of Learning Technologies

University of Minnesota, USA 